\title{
Under one roof? A population-based survey of patient use and preference for sexual health services
}

\author{
Debra Gray ${ }^{1}$, Catherine H. Mercer ${ }^{2}$, Anna Graham ${ }^{1}$, Rebecca S. French ${ }^{2}$, Chris Salisbury ${ }^{1}$ and \\ The One-Stop Shop Project Team ${ }^{1,2,3}$ \\ ${ }^{1}$ Academic Unit of Primary Health Care, University of Bristol, Bristol, UK \\ ${ }^{2}$ Centre for Sexual Health \& HIV Research, Research Department of Infection \& Population Sciences, \\ University College London, London, UK \\ ${ }^{3}$ Department of GUM, Royal Hallamshire Hospital, Sheffield Teaching Hospitals NHS Foundation Trust, Sheffield, UK
}

\begin{abstract}
Aim: To compare patterns of population service use and preference in areas with and without one-stop shop services. Background: A number of strategy documents have recommended adopting a more integrated approach to sexual health service provision. One proposed model of integration is one-stop shops, where services for contraception and sexually transmitted infections are provided under the same roof. Currently, the potential impact of one-stop shop services on patient service use and preference is unclear, particularly at a population level. Method: Three different models of one-stop shop were studied: a dedicated young persons' service, a specialist mainstream service, and an enhanced general practice. In each model, the one-stop shop site was matched to two control sites with traditional service provision. Random samples of male and female patients were selected from general practices close to either the one-stop shop or control sites. These patients received a postal survey asking about their use or preference for services for six sexual health needs. One-stop shop and control samples were compared using multivariate logistic regression. Findings: Of the 14387 patients surveyed, 3101 (21.6\%) responded. In the young persons' model, few significant differences were found in service use or preference between those living in one-stop shop and control site areas. In the specialist services model, women in the one-stop shop area were significantly more likely to cite specialist services for emergency contraception and abortion advice, when compared to those served by non-integrated control services. In the general practice model, respondents in the one-stop shop area were significantly more likely to cite general practice for all six sexual health needs. Overall, general practice was the preferred service provider cited for all sexual health needs, except condoms and pregnancy tests. These findings are discussed in terms of their implications for the provision of integrated sexual health services. In addition, key methodological issues and future research possibilities are identified.
\end{abstract}

Key words: delivery of health care, integrated; family planning services; genitourinary medicine; primary health care; sexual behaviour; sexual health services

Received 17 July 2008; accepted 9 April 2009; first published online 3 June 2009

Correspondence to: Dr Debra Gray, School of Psychology, University of the West of England, Frenchay Campus, Coldharbour Lane, Bristol BS16 1QY, UK. Email: debra.gray@ uwe.ac.uk

\section{Introduction}

Due to the increasing burden of poor sexual health (Nichol et al., 1999; Social Exclusion Unit,

(C) 2009 Cambridge University Press 
1999; Health Protection Agency, 2005, 2007), sexual health service provision has been placed high on the UK political agenda, with a focus on how to develop and deliver sexual health services in a way that addresses both public health concerns and patient needs (Department of Health, 2001; 2004). One recommendation is integrating services for contraception and services for the management of sexually transmitted infections (STIs), which historically developed independently despite these health concerns being closely and commonly related (Cates and Stone, 1992; Ward et al., 1995; Kane and Wellings, 1999). 'One-stop shops' where all services are provided on a single site or 'under one roof' - is one suggested model of integration, which is thought to provide a number of benefits, including being more responsive to patients' needs, and being more efficient in terms of both health outcomes and cost (Hardee and Yount, 1995; Bloxham et al., 1999; Schierhout and Hardon, 1999; Dawson et al., 2000).

Currently, there is little evidence to suggest that one-stop shops are any more acceptable or effective than traditional services that maintain their specialist interests. For example, community contraceptive clinics and genitourinary medicine (GUM) clinics that work collaboratively, but which do not provide integrated sexual health care on site (French et al., 2006). Also, while there is some evidence for increased user satisfaction with integrated services (Jones, 1996; Walsh, 1996; Bloxham et al., 1999; Hardon, 2003), there is currently little understanding of the effect that one-stop shop services will have on patterns of patient service use or preference at a population level. In general, little is understood about sexual health service use at a population level, particularly in terms of how people pick and choose different services for different sexual health needs. The evidence that is available suggests that most women (around 80\%) use general practice for contraceptive supplies (O'Sullivan et al., 2005), and that most sexually transmitted infection (STI) diagnoses in men and women are made in GUM clinics - although an increasing proportion are diagnosed in general practice (Cassell, 2006; Cassell et al., 2006a; 2006b). The 2000 National Survey of Sexual Attitudes and Lifestyles (hereafter NATSAL, 2000) also reports that around a third of women reporting diagnoses of genital Chlamydia in the last five years were diagnosed in general practice (Fenton et al., 2001a; 2005; Cassell, 2006). In addition, it is reported that around a half of men diagnosed with non-specific urethritis or urethral discharge are managed in general practice (Cassell et al., 2006a; 2006b).

Given current public health concerns around sexual health, and the problems regarding access to sexual health services (Nichol et al., 1999; Social Exclusion Unit, 1999; Health Protection Agency, 2007), it is important that we have a better understanding of sexual health service use and preference at a population level, as well as the effect of one-stop shops on these service choices. This is particularly important for general practice, given that evidence suggest that it has an important role to play in sexual health service provision, as well as the fact that one of the goals of the National Strategy for Sexual Health and HIV (Department of Health, 2001) is increasing the role of general practice in the management of sexual health. Additionally, while there is some agreement that one-stop shops might be a way of ensuring integration, there is less agreement about what such a service should look like (French et al., 2006), or where these services would be best located, for example in GUM clinics, walk-in centres, hospitals, or general practice. Developing a population-level understanding of service use and preference could help to address some of these questions.

In this paper, we report findings from a postal survey, which compared populations served by one-stop shops with those served by traditional sexual health service providers, in terms of their use or preference for a range of sexual health services, and in relation to six sexual health needs: condoms, contraception, emergency contraception, abortion advice, pregnancy tests, and tests for STIs. Three models of one-stop shop were studied: a dedicated young persons' service (A), a specialist mainstream service (combined community contraceptive and GUM clinics) (B), and an enhanced general practice model (C). Here, we present findings for all three models, and discuss these findings in terms of their implications for the provision of one-stop shop sexual health services. In addition, key methodological issues and lessons learnt from this study are identified and discussed in terms of their impact on the findings and implications for future research in this area. 


\section{Method}

This population survey formed part of a larger national evaluation of one-stop services for sexual health. The methodology of the evaluation is described in detail in a final evaluation report (One-Stop Shop Evaluation Team, 2007). In brief, a comparative case study design was used. The three one-stop shop sites were selected by the Department of Health in a separate bidding process, where one-stop shop services were invited to apply to participate in a national evaluation. The one-stop shop sites selected through this process were then matched with two control sites by the evaluation team. As far as possible, the one-stop shop and control sites were similar in terms of organization factors; for example, all general practices were group-teaching practices.
However, the control sites did not provide fully comprehensive and integrated services for both contraception and the management of STIs on one site. In addition, the one-stop shop and control site areas were matched for geographic and socio-demographic characteristics (eg, deprivation). A summary of the sexual health care provided in the one-stop shop and control services is given in Table 1.

One of the aims of the evaluation was to assess the impact of one-stop shops on patterns of service use at a population-level, and to determine the acceptability of one-stop shops at a local community level. In order to meet this aim, a postal survey of the local populations served by each of the three one-stop shops and six control sites was undertaken. The survey population was identified using general practice registers.

Table 1 Description of the one-stop shop and control site services

\begin{tabular}{|c|c|c|c|}
\hline & One-stop shop sites & Control sites & \\
\hline $\begin{array}{l}\text { Model A: Young } \\
\text { Persons' } \\
\text { Dedicated } \\
\text { Service } \\
\text { Setting: Seaside } \\
\text { town }\end{array}$ & $\begin{array}{l}\text { Clinic based in youth service. } \\
\text { Targets }<18 \text { year olds. Open one } \\
\text { afternoon per week ( } 4-6 \text { pm), } \\
\text { increasing to two afternoons } \\
\text { during the evaluation. Run by } \\
\text { a doctor and nurses. Most } \\
\text { contraceptive methods available, } \\
\text { including implants and intra- } \\
\text { uterine devices (IUD). Full sexually } \\
\text { transmitted infections (STI) } \\
\text { screen and microscopy on-site. }\end{array}$ & $\begin{array}{l}\text { Clinic based in youth } \\
\text { project. Advertised for } \\
<25 \text { year olds. Open one } \\
\text { evening per week (5-7 pm). } \\
\text { Nurse-led. No long-acting } \\
\text { reversible contraceptive } \\
\text { methods provided. } \\
\text { Chlamydia screening } \\
\text { introduced during the } \\
\text { evaluation. }\end{array}$ & $\begin{array}{l}\text { Based in community } \\
\text { contraceptive clinic. Advertised } \\
\text { for }<25 \text { year olds. Open one } \\
\text { evening per week ( } 5-7 \text { pm). Run } \\
\text { by a doctor and nurses. All } \\
\text { contraceptive methods } \\
\text { provided. Chlamydia screening } \\
\text { introduced during the } \\
\text { evaluation. }\end{array}$ \\
\hline $\begin{array}{l}\text { Model B: All-ages } \\
\text { Mainstream } \\
\text { Service } \\
\text { Setting: Greater } \\
\text { London }\end{array}$ & $\begin{array}{l}\text { Separate genitourinary medicine } \\
\text { (GUM), contraceptive, and young } \\
\text { people's ( }<18 \text { years) clinics } \\
\text { housed under one roof. Varying } \\
\text { levels of integration within clinics, } \\
\text { for example, all attendees of } \\
\text { GUM will have contraceptive } \\
\text { needs assessment. Integrated } \\
\text { pathways for easy referral } \\
\text { within site. }\end{array}$ & $\begin{array}{l}\text { GUM } \\
\text { Full GUM and HIV service } \\
\text { provided. Emergency } \\
\text { contraception available. } \\
\text { Young people's clinic } \\
\text { opened during course of } \\
\text { evaluation. } \\
\text { Contraceptive clinic } \\
\text { All methods, except } \\
\text { implants, offered. Open } \\
\text { twice a week. Chlamydia } \\
\text { testing pre-IUD insertion. }\end{array}$ & $\begin{array}{l}\text { GUM } \\
\text { In addition to full GUM service, } \\
\text { have HIV and young people's } \\
\text { clinics, and a contraceptive } \\
\text { clinic, although not integrated. } \\
\text { Contraceptive clinic } \\
\text { All methods provided. Open } \\
4 \text { days per week. Chlamydia } \\
\text { screening pre-IUD insertion } \\
\text { and for 'high risk' women. }\end{array}$ \\
\hline $\begin{array}{l}\text { Model C: General } \\
\text { Practice } \\
\text { Setting: Inner city }\end{array}$ & $\begin{array}{l}\text { } 7500 \text { patients. Houses sexual } \\
\text { health outreach project. All } \\
\text { contraceptive methods provided. } \\
\text { Full STI screen offered. Most STI } \\
\text { treatment and management } \\
\text { provided, including partner } \\
\text { notification. More complicated } \\
\text { cases, for example, HIV and } \\
\text { syphilis, referred to GUM. }\end{array}$ & $\begin{array}{l}\sim 6300 \text { patients. Most } \\
\text { contraceptive methods } \\
\text { offered, except condoms } \\
\text { and implants. Testing and } \\
\text { treatment for most STIs. } \\
\text { Partner notification } \\
\text { provision variable. }\end{array}$ & $\begin{array}{l}\text { } 7200 \text { patients. Provides oral } \\
\text { contraceptives and emergency } \\
\text { contraception. IUD provision } \\
\text { ceased over course of the } \\
\text { evaluation. Testing and } \\
\text { treatment for Chlamydia, } \\
\text { gonorrhoea, and syphilis. } \\
\text { Referred to local GUM for } \\
\text { partner notification. }\end{array}$ \\
\hline
\end{tabular}


In models $\mathrm{A}$ and $\mathrm{B}$, a list of all practices within two miles of each of the one-stop shops and their control sites was drawn up, and practices were approached in order of proximity until two agreed to participate. Across both models, the average distance of the recruited general practitioner (GP) service from the evaluated one-stop shop or control site was 0.9 miles. In models A and $\mathrm{B}$, six general practices were recruited - two from the one-stop shop area and two from each control area - making a total of 12 recruited practices across these models. Eligibility criteria were: being a group practice, a list size of more than 5000 , and being computerized. In model C, the onestop shop and the two control services were the evaluated general practices, and the sample was drawn from their own practice registers.

To identify a sample of the population to receive the survey, a stratified random sampling strategy was used. Patients were grouped according to age (16-25 years in model A, the young person's services, and 16-25 and 26-44 years in models $B$ and $\mathrm{C}$, respectively) and gender (male or female), and a random sample was drawn from each group. The sample size was calculated to have $80 \%$ power at a $5 \%$ significance level to detect differences in proportions (eg, the proportion being offered a particular form of contraceptive) of about $7 \%$ based on $50 \%$ versus $57 \%$, or $5 \%$ based on $10 \%$ versus $15 \%$.

The identified sample was first sent a letter about the evaluation. The survey, with a pre-paid envelope, was mailed one week later. One reminder (with another copy of the survey) was sent one week after that. Each mailing was accompanied by a personally addressed letter, on practice-headed paper, signed by a named GP. The format of these mailings was designed to maximize response rates. All survey packs were marked as confidential, and with a 'return to sender address' for those respondents who no longer resided at their GP registered address.

The survey asked about services respondents had visited for six sexual health needs, which were: condoms, contraception, emergency contraception, abortion advice, pregnancy tests, and tests for STIs. The given timeframe for service use was within the last six months for condoms and within the last year for all other sexual health needs. Participants could identify more than one service. Those who had not accessed a service were asked which one they would prefer to use for each of the identified sexual health needs. A comprehensive list of possible services was given, including: chemists (eg, Boots), GP, practice nurse, Brook, the Youth Advisory Service, STI clinic, Family Planning Clinic, A\&E, walk-in clinics, or the Internet. In all cases, the evaluation service, either one-stop shop or control, was identified by name in the survey distributed in each of the local areas. People were also asked to specify the reasons for their choice from a list of 17 options based on previous literature and piloting of the questionnaire, for example, location, opening hours, quality of service provision, or familiarity. All surveys were completed anonymously and were returned directly to the researchers. Data collection took place between January and August 2005.

\section{Data analysis}

In line with the case study approach, analyses compared the one-stop shop sample with its corresponding control samples. One model of onestop shop was not compared with another, as the populations served by the different models were very different. Some differences in the measured sexual health outcomes were observed between the two control sites. Hence, all comparisons for each one-stop shop are made to the average of the two control sites, by including appropriate terms in our logistic regression models. We calculated unadjusted odds ratios (ORs) and ORs adjusted for age, ethnicity, marital status, qualifications, numbers of sexual partners, and reported STIs or unplanned pregnancies in the last five years. Analysis also focused on the most cited service for a given sexual health need, and the three main reasons given for this choice. All analyses were done by gender, and each analysis combined actual service use (if participants had used any service(s) in the corresponding time frame) and preferred service use (preferred choice if participants had not used service(s) in the corresponding time frame). Separate analyses for actual and preferred service use revealed very similar results. Types of services were collapsed into: retail (chemists, supermarkets, or the Internet), general practice (GPs or practice-based nurses), and specialist services (family planning, GUM, and specialist youth services). When the term 'contraception' is used in the results it refers to all methods except condoms and emergency 
contraception, which were analysed separately. STATA $^{\mathrm{TM}}$ was used for all analyses. Significant results (at 0.05 ) are reported in bold in the tables. All results discussed refer to adjusted ORs.

\section{Results}

In all, 15251 surveys were mailed. After adjusting for undelivered letters returned by the Post Office, the response rate was 21.6\% (3101/14 387), with a higher response rate for women $(28.4 \%$; $2061 / 7266)$ than men $(14.6 \% ; 1010 / 7130)$. The low response rate is discussed below.

\section{Comparing one-stop shop and control areas}

In the young persons' services model, few statistically significant differences in service choice or preference were found when those living in one-stop shop or control areas were compared (see Table 2). Women living in the one-stop shop area were significantly more likely to report using, or preferring to use, a retail site for condoms, when compared to those living in the control areas. In addition, women in the one-stop shop area were significantly less likely to cite a GP service for this sexual health need. Women in the one-stop shop area were also less likely to report either actual or preferred use of other specialist services (which were not the dedicated young person's service) for contraception and pregnancy tests. On the other hand, men living in the onestop shop area were more likely to cite other specialist services for both condoms and STI tests when compared to those living in the two control site areas. However, it must be noted that at the time of the evaluation, the main focus of the two young person's control sites was the provision of contraception (and condoms) and there were few services offered directly to men.

A number of statistically significant differences were found in the specialist services model (see Table 3). Women living in the area with the onestop shop service were significantly more likely to report either using, or preferring to use, a specialist service (the evaluated one-stop shop) for emergency contraception and abortion advice, when compared to women accessing specialist services in the control areas. That is, women who had access to an integrated GUM and family planning service were significantly more likely to report either using or preferring to use that service, when compared to women with access to stand-alone GUM and family planning services for these sexual health needs. Women in the one-stop shop area were also significantly less likely to report using, or preferring to use, general practice for these same sexual health needs, when compared to those accessing the specialist control services.

In the general practice model (Table 4), a consistent pattern of results was found. For all six sexual health needs under consideration, respondents living in the one-stop shop area were significantly more likely to report either using, or preferring to use, their general practice (the onestop shop site), when compared to those accessing the general practices located in the control site areas. In addition, for most sexual health needs, respondents in the one-stop shop area were significantly less likely to cite specialist services or retail sites as their actual or preferred service choice, when compared to those living in the control site areas. For example, women were significantly more likely to choose to obtain contraception, abortion advice, and pregnancy or STI testing from general practice when resident in the one-stop shop area, than if resident in the control areas. Women were also significantly less likely to cite a specialist service for each of these sexual health needs. Men in the one-stop shop area were more likely to cite general practice as their actual or preferred service choice for STI testing, and were less likely to cite a specialist service for this sexual health need, when compared to those in the control areas. Finally, both male and female respondents in the one-stop shop area were significantly more likely to cite their general practice as their preferred site to obtain condoms, when compared to those accessing general practice in the control area. Whilst it must be noted that one of the control general practices did not offer condoms (see Table 1), it is interesting that men were also less likely to cite a retail service, and women a specialist site, for this sexual health need, if resident in the one-stop shop area.

\section{General patterns of service use and preference}

Overall, a consistent pattern of service use or preference was found in relation to particular 


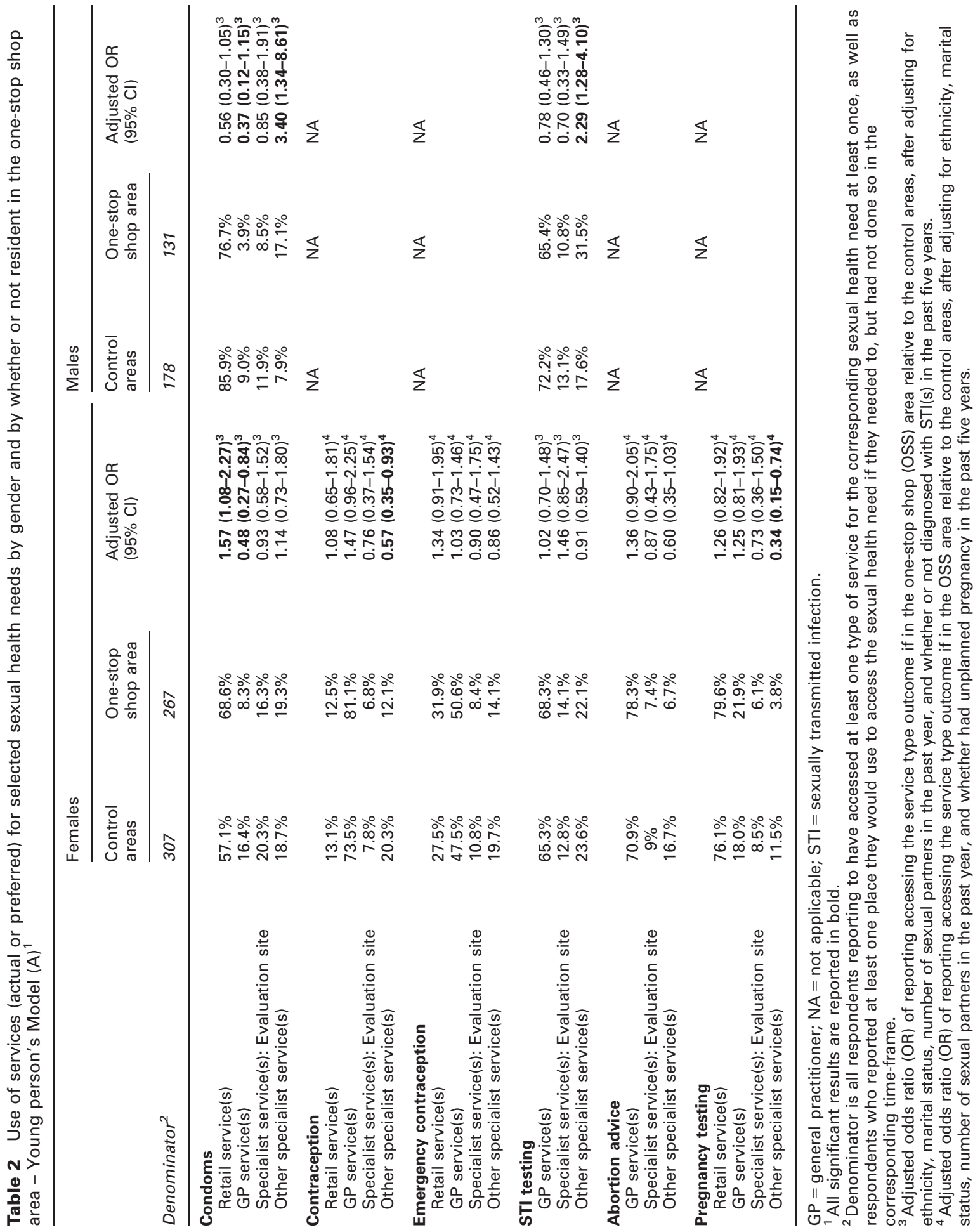

Primary Health Care Research \& Development 2009; 10: 223-235 


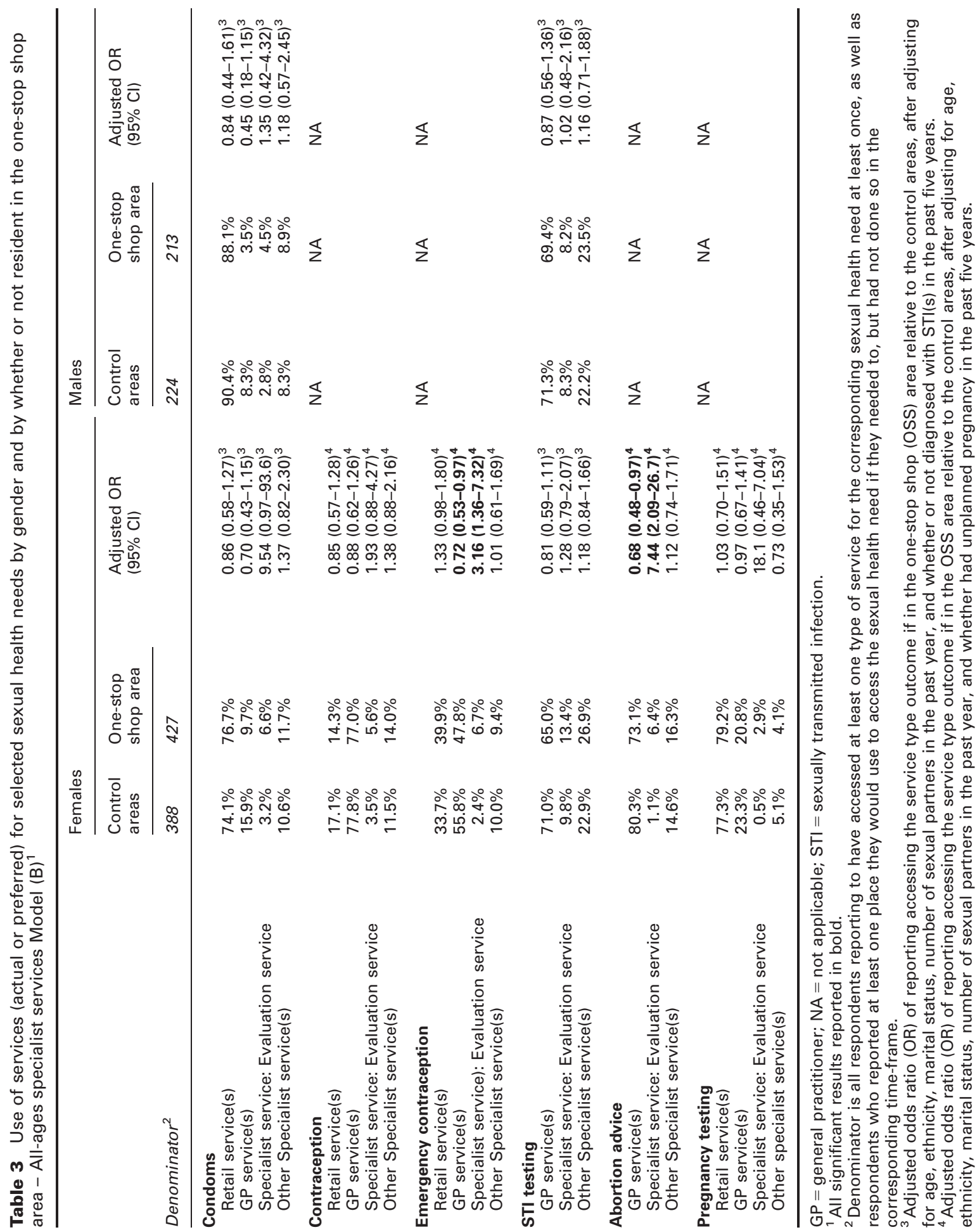

Primary Health Care Research \& Development 2009; 10: 223-235 


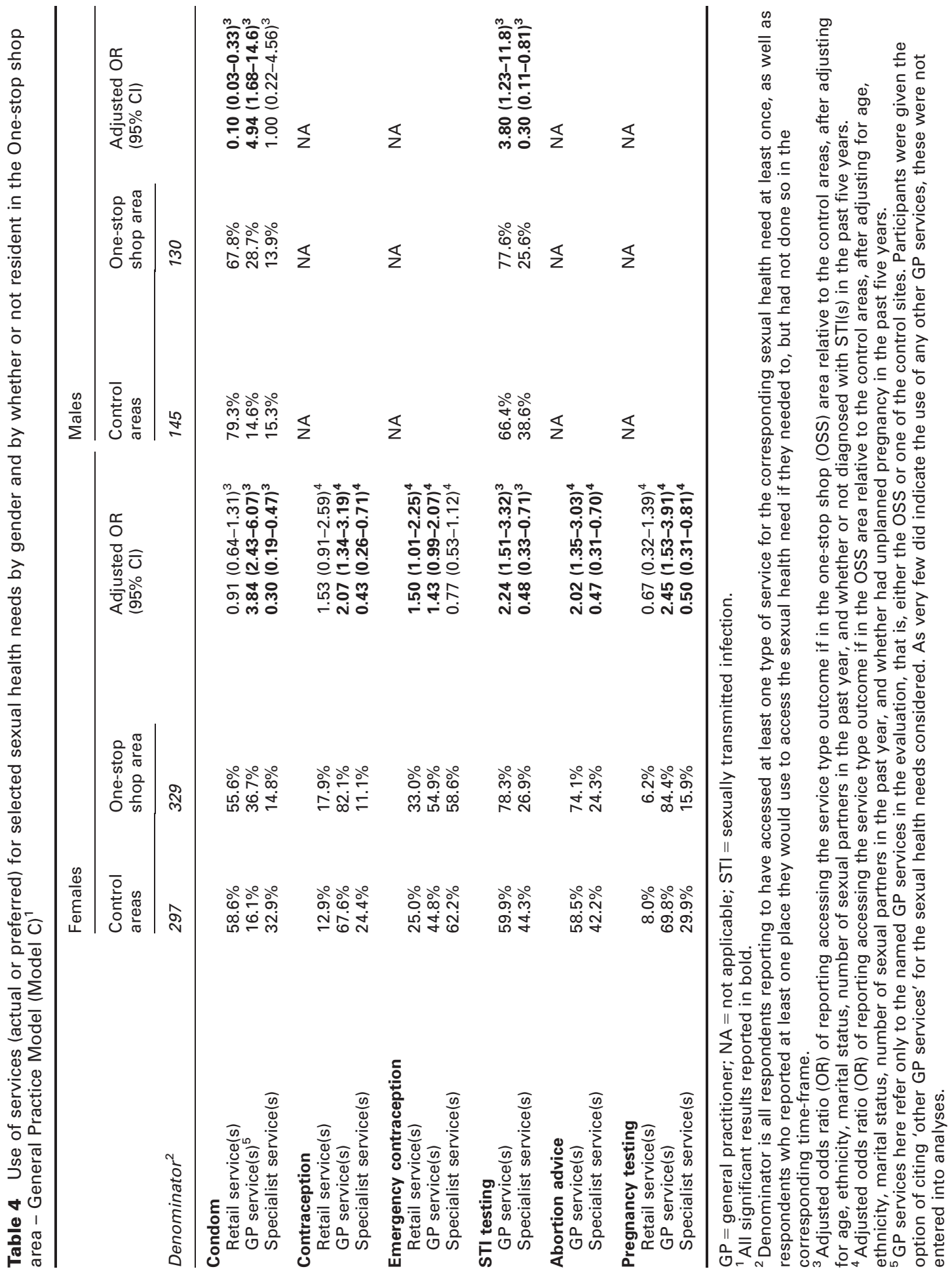

Primary Health Care Research \& Development 2009; 10: 223-235 
sexual health needs. Across all three models, a majority of men $(79.7 \% ; 829 / 1040)$ and women $(63.4 \% ; 1307 / 2010)$ chose retail site(s), such as chemists, the supermarket, or the Internet, as their preferred place for condoms. The reasons given for this service choice were primarily convenience-related, namely: that it is in a convenient location, that it has convenient opening hours, or that it is 'somewhere I go regularly'. Similarly, $77.7 \%(442 / 569)$ of women in model A, and $76.1 \%(620 / 815)$ of women in model B chose retail site(s) as their preferred place for pregnancy tests; again, for primarily convenience-related reasons such as location. However, this trend was not evident in model $\mathrm{C}$, where the most frequently cited service provider for pregnancy tests was general practice. Reasons given for this service preference included confidentiality, familiarity, and quality of service.

For emergency contraception, the picture was slightly more varied. Nearly half of the women (48\%; 992/2061) did cite general practice as their preferred choice for emergency contraception. However, a substantial proportion cited retail sites $(30.8 \% ; 635 / 2061)$ or specialist services $(30.7 \%$; 633/2061) for this sexual health need. For those choosing general practice, the reasons were the confidentiality of the service, the quality of the treatment and/or advice that they received, and that it was seen to be a comfortable environment with friendly staff. For those choosing retail site(s), the main reasons given were convenience-related. Finally, those who preferred to access emergency contraception from specialist service(s) did so because they saw this as a confidential service and as a comfortable environment with friendly staff.

For all other sexual health needs, general practice was clearly the most cited service choice, even where one-stop shop sites based in specialist mainstream or young persons' services existed. Of 2061 women, $1509(73.2 \%)$ cited general practice as their preferred place to get contraception, and 1390 (67.4\%) for abortion advice. Similarly, 66.5\% (692/ $1040)$ of men and $66.7 \%(1340 / 2010)$ of women cited general practice as their preferred service provider for STI testing. Reasons given for preferring general practice were the confidentiality of service, quality of advice or treatment received, and comfortable environment. Additionally, for STI testing, people reported preferring general practice because of its convenient location.

\section{Discussion}

The aim of the population survey was to compare patterns of service use or preference in populations which have access to one-stop shop sexual health services, with those serviced by a more traditional sexual health service provision. In the young persons' model (A), those living in the one-stop shop area were no more likely to report actual, or preferred, use of the young persons' specialist service, than those living in areas with nonintegrated young persons' services. In addition, specialist young persons' services were not the most frequently cited service provider for any of the sexual health needs considered. Thus, there is little evidence for the impact of the integrated young persons' services on service choice or preference at a population or community level.

This runs contrary to research which suggests that the one-stop shop model is particularly attractive to young people (Bloxham et al., 1999). However, the young persons' one-stop shop, which was evaluated as part of this study, was only open for a few hours each week, seeing only a small proportion of the young adult population. While this is similar to many dedicated young persons' services around the country, a service with longer opening hours may have shown a clearer effect. A surprising finding was the percentage of young people who cite general practice as their preferred service for a range of sexual health needs. It is generally believed that young people do not wish to access general practice for sexual health, especially for STI-related needs. However, we did not survey anyone under the age of 16 years, and had a small sample of participants between the ages of 16 and 18 years; therefore, it is possible that these groups may have responded differently to those aged 18 to 25 years. A population survey conducted as part of the Teenage Pregnancy Evaluation found that young people reporting sexual intercourse before their 16th birthday were significantly more likely to report use of designated young persons' sexual health services (French et al., 2007). In addition, data from other components of the evaluation showed that young people attending these services were often vulnerable and had quite complex needs (One-Stop Shop Evaluation Team, 2007). Further evidence from this survey seemed to suggest that it may depend on the type of user, as high-risk 
respondents (identified as having more than two sexual partners in the last year, an STI diagnosis in the last five years, or an unplanned pregnancy in the last five years) were more likely to access a young person's service for some sexual health needs (One-Stop Shop Evaluation Team, 2007). Therefore, while absolute numbers of young people in an area attending designated young persons' services may be relatively small, the public health impact may be much greater as these services are seeing those at higher risk of poor sexual health.

In the all-ages specialist mainstream model (B), women in the one-stop shop area were more likely to report actual or preferred use of an integrated GUM and contraceptive specialist service for both contraception and abortion advice, when compared to those who were living in areas with non-integrated specialist services. In addition, survey respondents in one-stop shop areas were less likely to cite general practice use or preference for these sexual health needs. However, again, the specialist services in either the one-stop shop or control sites areas were not the most cited service provider for any sexual health need. These findings seem to suggest that, while a majority of people did not report either accessing or preferring to access a specialist service for their sexual health needs, these specialist services were more likely to be chosen when an integrated rather than a stand-alone approach had been adopted for some sexual health needs. This may well be related to the reasons that people have for making particular service choices for particular sexual health needs, or alternatively, for this population group, one-stop shop services might be more acceptable for some sexual health needs than for others.

Finally, in the general practice model (C), respondents living in the one-stop shop area were more likely to cite the evaluated general practice for all six sexual health needs considered, when compared to those accessing the general practices in the control areas. In addition, those living in the one-stop shop area were less likely to cite specialist services or retail sites for some of these sexual health needs. These findings seem to suggest that where a one-stop shop is located in general practice, people are more likely to use, or prefer to use, that general practice for a range of sexual health needs. In addition, across all three models of one-stop shop, general practice was the most used or preferred service provider for most sexual health needs considered - the exceptions being more 'consumerist' sexual health needs such as condoms and pregnancy tests, where, overall, retail sites were preferred. These findings support earlier research which suggests that a majority of women access contraception from their general practice (O'Sullivan et al., 2005; French et al., 2009), and research which suggests that, since 2001, when it became available in pharmacies, the proportion of women obtaining emergency contraception from chemists or pharmacists has almost doubled, while the proportion of women obtaining emergency contraception from their GP or practice nurse is falling (O'Sullivan et al., 2005). However, it runs contrary to earlier studies on STI diagnosis (Cassell, 2006), as the majority of both men and women in this study cited general practice as their preferred service choice for STI testing. What is unclear from this though, is whether people who do go to general practice for STI testing are then being referred on to GUM clinics, as previous research has focused on STI diagnoses, rather than testing or management more generally.

\section{Study limitations}

The main limitation of this study is the low response rate, particularly in the male samples. Low response rates are frequently cited as a drawback of postal surveys, especially those in sensitive topic areas, and similar studies have achieved comparable response rates (Bates and Rogstad, 2000; Edwards et al., 2002; Fenton et al., 2001b). The sites in this study were in areas with high levels of socio-economic deprivation, and some were in areas with a high representation of minority ethnic groups. These factors are known to reduce uptake rates (Macleod et al., 2005). In addition, we did not have a reliable method of determining the proportion of our sample not living at their GP registered address. Earlier research using GP practice registers has shown that $27 \%$ to $32 \%$ of young adult patients on a GP practice register were no longer living at their registered address (Macleod et al., 1999; Macleod et al., 2005). Mobility is also higher in areas of high deprivation, and where there is a higher 
percentage of non-white residents (Macleod et al., 2005). Finally, other studies reported higher response rates after four or more mailings, or where non-responders were contacted by phone or visited by researchers at home (Macleod et al., 1999; Johnson et al., 2001; Edwards et al., 2002). Therefore, we may have had higher response rates if we had implemented some of these measures.

The low response rate for the study is problematic in terms of potential selection bias and the representativeness of the sample, and because of the reduction in the power of the study. This is compounded by the fact that those people responding to a postal survey sent in the name of their registered general practice may not fully represent all users of sexual health services. Other elements of the onestop shop evaluation highlight that some target groups, such as young people, gay men and some people from minority ethnic groups, are concerned about confidentiality in general practice. These people may have been less likely to respond to this postal survey, even though it was returned to the researchers and not the general practice.

Finally, it is worth noting that the general practices evaluated in model $\mathrm{C}$ are not necessarily representative of general practices across the country. For example, all three of the practices selected had some interest in sexual health and all were group practices.

\section{Conclusions}

The key conclusions and lessons learnt from this study are identified in Box 1. Given the methodological limitations of the study, it is clear that further research at the population level is needed before definite policy implications can be drawn. Future research in this area will need to carefully consider the difficulty of accessing hard-to-reach populations, especially in relation to the impact of mobility and socio-economic deprivation on response rates, when this is characteristic of the population of interest (Macleod et al., 2005). For example, the reliability of methods to capture socalled 'ghost' respondents, who are not resident at their registered addresses, must be addressed. Many acknowledge that postal research can provide a simple and cost-efficient means of reaching a widely dispersed population, some of whom would not normally attend a healthcare setting

\section{Box 1}

\section{LESSONS LEARNT}

- General practice was the most cited service provider for most sexual health needs considered and, where a one-stop shop exists in general practice, it appears to be generally well received.

- Several factors were identified as being important for how people choose particular sexual health services for particular sexual health needs, for example, convenience or confidentiality.

- Future research will need careful reflection on the methodological limitations of postal survey research, and will need to consider the appropriateness of this methodology for collecting population-based sexual health data.

- Future research should also focus on general practice as a provider of integrated sexual health services to a variety of service users.

(Bates and Rogstad, 2000). However, it also needs to be recognized that this is not always the case. Instead, many of the difficulties of doing postal research, for example, the need for incentives, coloured ink questionnaires, personally addressed letters, and recorded delivery to bolster response rates (Edwards et al., 2002), can impact considerably on both cost and time efficiencies. Future surveys of this type will need to consider these issues

However, despite these methodological problems, it is clear that the main strength of this study is that there are no other sources of comparable data on population preferences for different types of sexual health services. NATSAL 2000 does provide data about service use for contraceptive advice or supplies, and service preference for professional advice (Johnson et al., 1994; Johnson et al., 2001; French et al., 2009). In contrast, this study has asked about actual and preferred service use for a range of sexual health needs, and provides data on one-stop shop versus more traditional models of service provision. Thus, this study provides important population-level data on sexual health services choices, and the effect of 
one-stop shops on these services choices. The findings from this study suggest that general practice can offer opportunities for meeting a majority of peoples' sexual health needs and that, where a onestop shop exists in general practice, these services are generally well received by communities. This is supported by other parts of the national one-stop shop evaluation, which suggest that more comprehensive sexual health care can be provided within general practice, although there is clear consensus that this should be done with support from specialist services (One-Stop Shop Evaluation Team, 2007). Future research is needed in this area, particularly focusing on general practice as a provider of integrated sexual health services to a variety of service users.

\section{Acknowledgements}

The National Evaluation of One-Stop Shops (OSS) in Sexual Health was funded by the Department of Health, and the study was approved by the Trent Multi-centre Research Ethics Committee (04/ MRE04/30). The views expressed in this paper are those of the authors, and not necessarily those of the Department of Health.

The members of the OSS project team are: University of Bristol: Jo Coast, Debra Gray, Anna Graham, Susan Hamilton, Sandra Hollinghurst, and Chris Salisbury. University College London: Caroline Coope, Rebecca French, Makeda Gerressu, Catherine Griffiths, Catherine Mercer, Kevin Miles, Angela Robinson, and Judith Stephenson. Royal Hallamshire Hospital, Sheffield: Karen Rogstad. The authors would also like to thank the members of the advisory group: Jan Barlow, Paula Baraitser, Hansa Patel-Kanwal, Roslyn Kane, Gill Bell, Alan McOwan, Ian Simms, Jackie Cassell, and Connie Smith. All participating sites and survey respondents are duly acknowledged for their help.

\section{References}

Bates, S.M. and Rogstad, K.E. 2000: Postal research: too many problems? Sexually Transmitted Infections 76, 332-34.

Bloxham, S., Capstick, S. and Greenwood, A. 1999: Combining GUM and contraceptive services for young people: profile of an innovative clinic. British Journal of Family Planning $25,18-21$.

Primary Health Care Research \& Development 2009; 10: 223-235
Cassell, J. 2006: Estimating STI morbidity in primary care. British Medical Journal 82, 67-71.

Cassell, J., Mercer, C.M., Sutcliffe, L. et al. 2006a: Trends in sexually transmitted infections in general practice 1990-2000: population based study using data from the UK general practice research database. British Medical Journal 332, 332-34.

Cassell, J., Mercer, C.M. and Fenton, K.A. 2006b: A comparison of population diagnosed with Chlamydia in primary care with that diagnosed in sexual health clinics, and its implications for a national screening programme. Public Health 120, 984-88.

Cates, W. Jr and Stone, K. 1992: Family planning, sexually transmitted diseases and contraceptive choice: a literature update - Part 1. Family Planning Perspectives 24, 75-84.

Dawson, S.G., Callander, N., Roche, C., Kingsland, T. and Desmond, N. 2000: Integrated sexual healthcare: the development and review of one model of service delivery. International Journal of STD and AIDS 1, 428-34.

Department of Health. 2001: The national strategy for sexual health and HIV. London, UK: HMSO.

Department of Health. 2004: Making healthier choices easier. London, UK: HMSO.

Edwards, P., Roberts, I., Clarke, M. et al. 2002: Increasing response rates to postal questionnaires: systematic review. British Medical Journal 324, 1183-92.

Fenton, K.A., Korovessis, C., Johnson, A.M. et al. 2001a: Sexual behaviour in Britain: reported sexually transmitted infections and prevalent genital Chlamydia trachomatis infection. Lancet 352, 1851-54.

Fenton, K.A., Johnson, A.M., McManus, S. and Erens, S. 2001b: Measuring sexual behaviour: methodological challenges in survey research. Sexually Transmitted Infections 77, 84-92.

Fenton, K.A., Mercer, C.H., Johnson, A.M. et al. 2005: Reported sexually transmitted disease clinic attendance and sexually transmitted infections in Britain: prevalence, risk factors and proportionate population burden. Journal of Infectious Diseases 191 (Suppl 1), S127-98.

French, R.S., Coope, C.M., Graham, A. et al. 2006: One-stop shop versus collaborative integration: what is the best way of delivering sexual health services? Sexually Transmitted Infections 82, 202-06.

French, R.S., Mercer, C.H., Kane, R. et al. 2007: What impact has England's Teenage Pregnancy Strategy had on young people's knowledge of and access to health services for contraceptive advice and supplies? Findings from the Teenage Pregnancy Strategy Evaluation. Journal of Adolescent Health 41, 594-601.

French, R.S., Mercer, C.H., Johnson, A.M. et al. 2009: Use of contraceptive services in Britain: Findings from the second National Survey of Sexual Attitudes and Lifestyles. The Journal of Family Planning and Reproductive Health Care $35,9-14$.

Hardee, K. and Yount, K.M. 1995: From rhetoric to reality: delivering reproductive health promises through integrated services. USA: Family Health International Working Paper Series. 
Hardon, A. 2003: Reproductive health care in the Netherlands: would integration improve it? Reproductive Health Matters 11, 59-73.

Health Protection Agency. 2005: Mapping the issues: HIV and other sexually transmitted infections in the United Kingdom. London, UK: HPA.

Health Protection Agency. 2007: Testing Times: HIV and other Sexually Transmitted Infections in the United Kingdom. London, UK: HPA.

Johnson, A.M., Wadsworth, J., Wellings, K. et al. 1994: Sexual attitudes and lifestyles. Oxford: Blackwell Scientific Press.

Johnson, A.M., Mercer, C., Erens, B. et al. 2001: Sexual behaviour in Britain: partnerships, practices and HIV risk behaviours. Lancet 358, 1835-41.

Jones, M. 1996: Clients express preference for one-stop sexual health shop. Nursing Times 96, 32-33.

Kane, R. and Wellings, K. 1999: Integrated sexual health services: the views of medical professionals. Culture, Health and Sexuality 1, 131-45.

Macleod, J., Rowsell, R., Horner, P. et al. 1999: Postal urine specimens: are they a feasible method for genital chlamydial infection screening. British Journal of General Practice 49, 455-58.

Macleod, J., Salisbury, C., Low, N. et al. 2005: Coverage and uptake of systematic postal screening for genital Chlamydia trachomatis and prevalence of infection in the
United Kingdom general population: cross sectional study. British Medical Journal 330, 940-44.

National Survey of Sexual Attitudes and Lifestyle. 2000: Johnson, A., Fenton, K., Copas, A. et al.

Nichol, A., Catchpole, M., Cliffe, S. et al. 1999: Sexual health of teenagers in England and Wales: National Centre for Social Research. Analysis of national data. British Medical Journal 318, 1321-22.

One-Stop Shop Evaluation Team. 2007: Evaluation of One-Stop Shop Models of Sexual Health Provision. Retrieved 13 March 2009 from http://www.dh.gov.uk/en/Publicationsand statistics/Publications/PublicationsStatistics/DH_083200.

O'Sullivan, I., Keyse, L., Park, N., Diaper, A. and Short, S. 2005: Contraception and sexual health, 2004/05. London, UK: HMSO.

Schierhout, G. and Hardon, A. 1999: The integration of primary health care services: A systematic literature review. Durban: Health Systems Trust.

Social Exclusion Unit. 1999: Teenage Pregnancy. London, UK: Stationery Office.

Walsh, J. 1996: Family planning provision in genitourinary medicine: a quiet revolution. British Journal of Family Planning 22, 27-30.

Ward, H., Kubba, A., Bradbeer, C. et al. 1995: Consensus workshop on sexually transmitted diseases and contraception: sexual health promotion and service delivery. Faculty of Family Planning and Reproductive Health Care, Faculty of Public Health Medicine: MSSVD. 